\title{
Research on Yunnan Vegetable Export Industry in the Context of "Belt and Road Initiative"
}

\author{
Wenhua Yang* \\ International Business School \\ Yunnan University of Finance and Economics \\ Kunming, China \\ 362941296@qq.com
}

\author{
Piju Kang \\ International Business School \\ Yunnan University of Finance and Economics \\ Kunming, China \\ 1343681968@qq.com
}

\begin{abstract}
Yunnan province is located in the core place of southwest of China and therefore becomes a strategic position in the context of "Belt and Road Initiative" because of its special geographical location and diverse natural resources. "Belt and Road Initiative" has brought opportunities for Yunnan's vegetable industry as well as some challenges since Yunnan's vegetable industry has some problems, such as low industrialization, high logistics costs and low added values. This paper puts forward some suggestions that the local governments in Yunnan should increase investment in areas ranging from enterprise technology, vegetable product processing, large-scale vegetable planting, logistics infrastructure to vegetable product testing system while the relevant enterprises should take advantage of "Belt and Road Initiative" and improve its industrialization and the development of organic vegetables based on SWOT analysis.
\end{abstract}

Keywords: Belt and Road Initiative, Yunnan's vegetable industry, SWOT analysis

\section{INTRODUCTION}

"Belt and Road Initiative" (BRI) originally was put forward in 2013 by Xi Jinping, President of People's republic of China. This initiative expresses that China is committed to strengthening interconnection with other developing countries, basically Asian, African, and European countries through further enhancing infrastructure and institutional cooperation.

BRI aims to provide networks that will allow for a more efficient and productive free flow of trade as well as further integration of international markets both physically and digitally. BRI will take advantage of international transport routes as well as core cities and key ports to further strengthen collaboration between China and other developing countries and regions.

The ultimate goal of BRI is to establish an "international community with shared interests, destiny, and responsibility." BRI covers more than 60 countries and regions in Asia, Europe, Oceania as well as the East Africa, with 4.4 billion in population (Fan , 2018) [1]. Therefore, enterprises of Yunnan are meeting great opportunities and challenges now.

\section{LITERATURE REVIEW}

Vegetable industry is one of the economic backbone *Corresponding author industries in Yunnan. In the past years, most scholars focus their researches on discussing the advantages and the problems of vegetable industry development in Yunnan Province. Compared with other provinces in China, Yunnan has unique advantages. Yunnan Province has diverse agricultural ecosystems, which makes it possible to grow almost all the vegetables all the year round. At the same time, some disadvantage factors in Yunnan also hinder the development of vegetable industry. Typical problems include the following: most vegetables are primary processed products and fine(deep) processed products are rare on the market; the package of vegetables are rough and simple, and the vegetable logistics infrastructure in Yunnan is backward ( Zhang etc. 2012; Long, etc. 2013; Zhou,etc. 2018). [2][3][4]

Some scholars focus their study on discussing the existing advantage and potential of Yunnan vegetables exported to Singapore from the perspective of demand and supply in Singapore vegetables market (Zhao. Etc,2017) [5]. Xu and Ye (2017)[6] put forward some sustainable strategies of developing pollution-free vegetable industry in Yunnan after analyzing the absolute advantages of growing pollution-free vegetables.

Yuan analyzed the agricultural cooperation investment environment between China and Myanmar. This study suggested that the agricultural cooperation between the two countries is prospective under the background of BRI because of the feature of complementarity trade (Yuan, 2017)[7].

The review of literature indicates that vegetable industry development in Yunnan is a major concern for Chinese scholars, but their studies failed to connect it with current Chinese national development strategy BRI. Some scholars focus their studies on agricultural cooperation between China and BRI countries, but few researches discuss the vegetable industry in Yunnan in the context of BRI. Therefore, this paper tries to discuss the development of vegetable industry in Yunnan in the context of BRI by using SWOT analysis on the basis of the literature review and second-hand statistics.

\section{CURRENT SITUATION OF YUNNAN VEGETABLE INDUSTRY}

The unique geographical location of Yunnan makes it an important province in the context of BRI since Yunnan 
borders with Southeast Asian countries, including Myanmar, Vietnam and Laos. It is also close to South Asia, West Asia, the Pacific Ocean and the Indian Ocean. Yunnan has been known as "the vegetable basket and the garden of China" for its abundant and diverse high-quality vegetables and fresh cut flowers. Every day, tons of fresh vegetables and flowers are marketed outside of Yunnan and other countries. Agricultural industry, especially vegetables industry, has been developing rapidly after the BRI being put into practice.

Yunnan is a major province for vegetable cultivation.According to the National Bureau of Statistics of China, the vegetable planting area in Yunnan Province was only $8,429,000 \mathrm{mu}$ in 2007 and was increased to $15,620,000$ mu in 2016, an increase of $85.1 \%$ in the past ten years.The average increase is $8.51 \%$ every year. Statistics of Yunnan Provincial People's Government Network also showed that vegetable planting area in Yunnan reached 16.2721 million acres in 2017 with many vegetable growing bases. Statistics from Yunnan Entry-Exit Inspection and Quarantine Bureau showed (January 2016) that there are over 40 vegetable planting bases which are exclusive for Hong Kong and Macao, covering an area of 36,200 acres[8].

Vegetable production output of Yunnan was 11,133,000 ton in 2007 and was increased to 19,866,000 ton in 2016, with an average annual growth rate of 7.68\%[9]. Yunnan Provincial People's Government statistics also showed that vegetable planting areas in Yunnan in 2017 increased by $4.29 \%$ compared with that of the same period of 2016, and vegetable output increased by $5.54 \%$ with 20.7776 million tons. The agricultural output value was estimated to be RMB 44.67 billion, an increase of $4.37 \%$, accounting for $11.8 \%$ of the total output value of agriculture, forestry and animal husbandry. The output of vegetable industry ranks the first place in the characteristic economy in Yunnan Province. The vegetable planting area of Yunnan ranks the eleventh and its output ranks the twelfth in China.

Nearly $64 \%$ of Yunnan's vegetables are marketed to other provinces of China and other countries and regions as well. It's reported by China Daily in 2017 that the export volume of vegetables in Yunnan Province was 1.152 million tons, about 1.41 billion US dollars in value, and more than 60 kinds of vegetables were exported to other countries. ASEAN is an important vegetable export region of Yunnan vegetables. For example, in Hanoi, Vietnam, Yunnan's vegetable market share has reached more than $70 \%$. However, Yunnan's vegetables mainly go to the domestic markets, accounting for $60 \%$ while only $4 \%$ are exported to other countries.

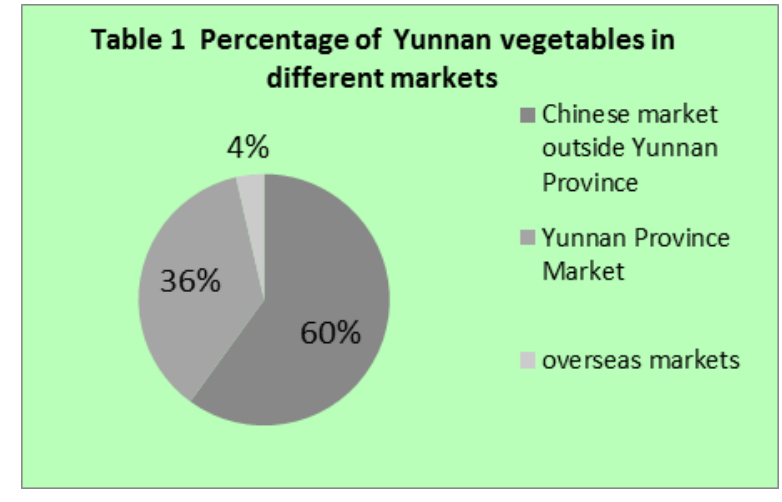

\section{SWOT ANALYSIS OF YUNNAN'S VEGETABLE INDUSTRY}

To further understand the current situation of Yunnan vegetable industry and vegetables enterprises development, this paper adopts SWOT analysis to identify the opportunities and challenges that Yunnan vegetable industry will be faced in the context of BRI.

\section{A. Strengths}

1) Unique and Diverse Natural Environment

Yunnan is located in the low latitude plateau with diverse ecological environments. Such environment is suitable for planting almost all vegetables in four seasons. There are high mountains and small hills and basins as well. There are diverse climates even in one area and such climates allow various types of vegetables to grow all the year round. Besides, the unique geographic features such as strong and long-time sun shine in the daytime and dramatic decrease in temperature in night time make the quality of vegetables and fruits superior to those of other provinces.

\section{2) Low Cost and Competitive Prices}

Yunnan Province has abundant labor resources. The labor cost is relatively low and the investment in vegetable production facilities are also lower than those of other major producing provinces (regions) in China. As a result, the production cost of vegetable products is significantly lower than those of other provinces. On the whole, Zhang's study showed that the domestic price of vegetable products in Yunnan Province is only one eighth to one fifth of that in developed countries. In other words, the price of the same quality vegetables is significantly lower than that in the international market, thus forming an obvious price advantage of vegetable products in Yunnan Province (Zhang, 2012) [10] .

\section{3) Location Advantage}

Yunnan has obvious geographical advantages. Yunnan's neighbouring provinces in China are Sichuan, Guizhou, Guangxi and Tibet; and Yunnan's neighbouring countries are Myanmar, Laos and Vietnam. Yunnan plays an important role in the strategy of BRI because Yunnan acts as the core province which connects the South Asia and Southeast Asia. Yunnan's opening to Southeast Asia and South Asia makes it the best province in the west of China. Because of the location advantages and high-quality vegetable production, Yunnan vegetables exporting markets to Hong Kong and Macao, 
Singapore, Japan and Thailand as well as the surrounding countries have remained strong in the past years.

\section{B. Weaknesses}

\section{1) Low Degree of Industrialization}

The low degree of industrialization of Yunnan vegetables can be seen from two aspects. One is decentralized planting areas, and the other is weak production management.

First, the size of vegetable cultivation is relatively small and scattered. According to the primary statistics of this study, about twelve million hectares vegetable areas are scattered in every county of Yunnan, ranging from 2260 hectares ( Diqing Tibetan Autonomous Prefecture) to 132000 hectares (Wenshan Zhuang and Miao Autonomous Prefecture). Vegetable cultivation and management has not been developed into modernized enterprises with standard planting and management system. As a result, most vegetable enterprises in Yunnan are now still small in size and lack the ability to prevent market risks. Second, the development of vegetable industry in Yunnan lacks international marketing talents. Most vegetable planting and processing enterprises are not only small in size, but also poor in production conditions. Advanced technology and mature management are still in demand. Smallscale decentralized operation hinders the improvement of technology and management level, making it more difficult to improve the level of standardized production and brand sales.

\section{2) Insufficient Transport Capacity}

Yunnan has the advantage of being located in the frontier of China. However, most cities and towns are located in uneven plateau with deep valleys or steep mountains. Most farmers live in mountainous villages. On top of this, people are living in small groups in small villages in different mountains. Statistics of Yunnan government shows that 129 cities and towns have now been connected by highways in Yunnan province in 2018, which is 5098 kilometers in total. Even so, transportation conditions in Yunnan are far backward compared with that of other provinces in China. As a result, Yunnan's logistics infrastructure capacity is seriously inadequate.

In recent years, Yunnan provincial government has increased the investment to encourage the development of plateau-specific agricultural products. In some areas, regional cold chain logistics centers for Southeast Asia and South Asia have been built to meet the development needs of local agricultural products. However, the existing facilities cannot meet Yunnan's vegetable production capacity. As far as the overall situation of Yunnan Province is concerned, the cold chain logistics infrastructure is seriously inadequate, and refrigerated transport vehicles are scarce and cannot meet the market demand. At present, more than $90 \%$ of vegetables are still transported and stored under indoor temperature, and the loss rate of this process is as high as $30 \%-35 \%$, while the loss rate in developed countries is controlled below $5 \%(\mathrm{Hu}$, 2013)[11]. Therefore, advanced logistics infrastructure is essential to reduce the loss rate and guarantee the quality of vegetables.

\section{3) Low Post-harvest Processing Capacity of Vegetables}

The post-harvest processing technology of Yunnan vegetables is less developed. The experience of developed countries indicates that among the revenue of the vegetable industry, production only accounts for $25 \%$, the circulation accounts for $42 \%$, post-production processing and processing account for 33\% (Zhang and Ye, 2013)[12] . In most developed countries, post-harvest commercialization of vegetables can be increased by $40 \%-60 \%$, and the packaging rate of vegetables in developed countries is almost $100 \%$ while Yunnan vegetable products lack sorting and grading after harvest and vegetables quality cannot be guaranteed. What's worse, most enterprises just use simple package which devalue the grade of vegetable products. At present, the packaging rate of vegetable commercialization in Yunnan Province is only 25\%. Most agricultural products exported from Yunnan Province are raw materials and primary-processed products, with low added value and some even have no independent brands. At present, only $20 \%$ of Yunnan vegetables are labeled by Yunnan local vegetables enterprises. Even so. They have low brand recognition (Zhou, 2018)[13] .

\section{4) Weak Innovation}

The obvious advantages of biodiversity and unique climatic conditions have contributed to the development of Yunnan's vegetable industry. However, high-priced foreign seeds or variety patent rights to develop the vegetable industry still need to be purchased or introduced from other countries due to the weak independent innovation capability.

As the largest country in the global production and export of vegetables, China failed to have the initiative to develop and produce vegetable seeds. Two-thirds of the vegetable varieties grown by farmers come from foreign seeds companies. Research and Development of seed production is the "final bottleneck" for the development of Yunnan green vegetable industry. To promote Yunnan vegetables to the world, the seed industry will become a "different force" in the vegetable industry in Yunnan.

\section{Opportunities}

1) Huge Potential Market

As discussed above in this paper, Yunnan's unique location makes it convenient to export Yunnan vegetable products to many neighboring countries and regions in Asia. Currently, Thailand, Singapore and Malaysia, Japan and Korea, Hong Kong and Macao of China are the major vegetable markets of Yunnan. Statistics shows that in vegetable markets of China Hong Kong and Macau, Yunnan vegetable accounts for approximately 33\%; 50\% market share in Bangkok, Thailand and over $70 \%$ in Hanoi, Vietnam.

Table 2 The market Share of Yunnan's Vegetable in Different Markets 


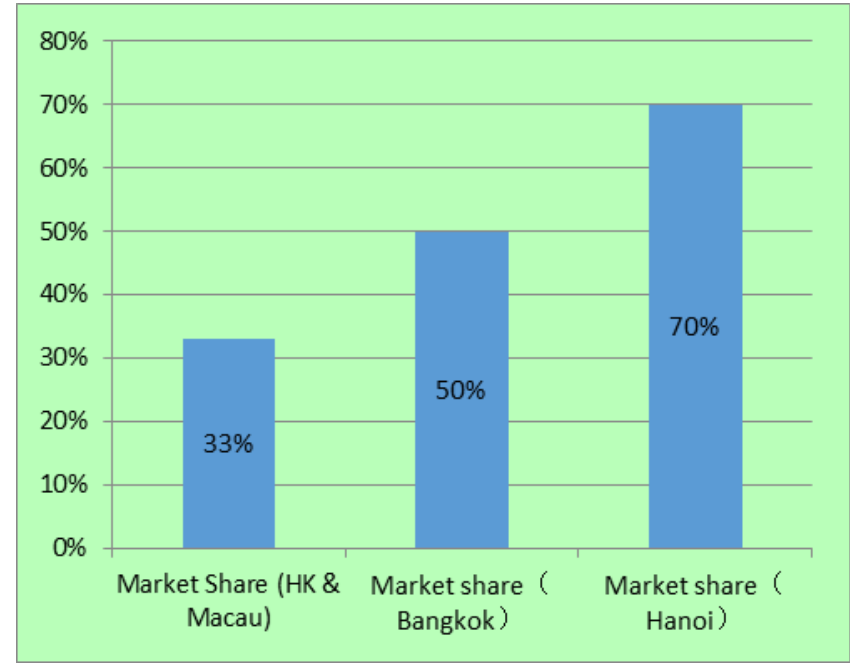

Source: http://ww. sohu. com/a/271091300 346681 [14]

Unfortunately, Only a small part of Yunnan vegetables entered into the markets of Japan, Singapore and Korea. Yunnan vegetable enterprises should expand its marketplaces by taking the new platform--Yunnan Pilot Free Trade Zones

(YPFTZ) , which was established in Aug. 2019 in Yunnan province. YPFTZ consists of Kunming free trade zone, Honghe free trade zone and Dehong free trade zone, totally covering 119.86 square kilometers. YPFTA aims to build an open international channel connecting South Asia and Southeast Asia by supporting innovation and economic development. YPFTZ will definitely facilitate trade and promote cross-border E-Commerce development between Yunnan and southeast Asian countries. YPFTA will be beneficial for the development of Yunnan vegetable industry.

\section{2) Policy Support from the Government}

It has been proved true that government support can greatly boost the economy. Take Thailand as an example, on October 1 , 2003, China and Thailand canceled the trade tariffs on 108 vegetables and 80 kinds of fruits between the two countries, and starting the "zero tariffs" policy. The export and import of vegetables and fruits has been increased sharply since then. It is estimated that vegetable trade volume reached 3.4 billion yuan in 2010 (Yang, 2010)[15]. Under the background of BRI, Yunnan government has taken effective measures aiming to build a world-class "green food brand" vegetable products. Notice of Measures of Promoting Investment in Nurturing Leading Green Food Industry Enterprises in Yunnan Province ( pilot edition) has been issued. Favorable policy support from the governments in capital investment, infrastructure improvement., together with brand cultivation and market development will definitely promote the modernization of vegetable industry in Yunnan.

\section{Threats}

\section{1) Strong Competitors}

Yunnan vegetable industry is facing serious challenges at home and abroad. In the international vegetable market, Thailand has become the biggest competitor in Southeast Asia. Thailand has been a major exporter to European countries, typically for tropical fruits and vegetables. In the domestic vegetable market, Shandong province is the largest and most advanced vegetable producer. According to the latest data of National Bureau of Statistics (NBS) in 2016, the total vegetable output in China is 797.797 million Kilograms. Shandong again ranks the first with 103.27 million Kilograms, while Yunnan only ranks the 12th, with output of 19.686 million kilograms. Four provinces including Henan, Hebei, Sichuan and Guangxi are all ahead of Yunnan.

\section{2) Green Barriers}

"Green Barriers" is defined as the compulsory and arbitrary Green regulations, standards and conformity assessment procedures of the importing countries in the name of the protection of human health and environment that actually form barriers to trade with an aim to protect its home market and domestic products (Sargen, 2006)[16]. Countries and regions which have green barriers not only carry out strict environmental protection law and harsh green technology standard, but also implement strict quarantine system to evaluate the Pesticide Residues in vegetables, making it more difficult for Yunnan vegetables to expand to the international marketplaces.

\section{COUNTERMEASURES FOR PROMOTING YUNNAN VEGETABLES INDUSTRY}

\section{A. Improving the Logistics System}

Vegetable exports are inseparable form strong logistics support. However, most logistics companies in Yunnan are transformed from traditional warehousing and transportation enterprises. From the perspective of service, they are still simple warehouse storage and cargo transportation and there are few high-level integrated third-party logistics service companies for agricultural products to keep the quality of vegetables. Under the background of BRI, this paper puts forward the following suggestions:

1) Constructing the advanced core logistics circle of Dianzhong City Group with Kunming as the center and five radiation ports of Hekou, Mohan, Jiegao, Funing Port and Shuifu Port, making Kunming an international inland port to drive Yunnan's development. Kunming should be built to be the economic radiating center in Southwest of China which connects the East, Middle and West China as well as connects Southeast Asia, South Asia, West Asia, Southern Europe and Africa.

2) Transforming the highway, railway and water transportation hub freight station with best conditions into some logistics distribution centers. Advanced logistics distribution center can integrate freight, warehousing, processing, packaging, distribution and information integration.

Vegetable industry in Yunnan has prospective future. Very soon distribution logistics centers will be reality in Yunnan, because as a part of the Silk Road Economic Belt and the 21st Century Maritime Silk Road initiatives, the infrastructure, such as highways, railways and airports will been improved dramatically. According to Yunnan's transportation blueprint, investment in road and water transportation will reach 100 
billion yuan ( $\$ 15.39$ billion) in Yunnan in 2016 and is expected to up to 500 billion yuan by 2020[17].

\section{B. Enlarging Technical Investment and Improving Post-} harvest Processing Capacity of Vegetables

Currently, the main vegetable products exported from Yunnan Province are regarded as primary products with little added-value. In the future, highly processed vegetables should be the main trend. Fresh vegetables, as well as canned vegetables and instant vegetable products will appear in the market.

\section{Improving Large-scale Planting and Industrialization}

Although vegetables have become increasingly important, farmers, especially family-based farmers cannot benefit from their production. Decentralization and backward technology are the main modes of vegetables planting in Yunnan, which obviously cannot meet the needs of large markets. Except Tong Hai county planting base (the planting area is around 22400 $\mathrm{hm}^{2}$ in Yuxi county) most existing planting bases are still not big enough, compared with those in Shandong province-Shou Guang, China's vegetable town named by the State Council.

\section{Establishing the Quality Inspection System}

As is known, the most important index to evaluate the quality of vegetables is the Pesticide Residues. The vegetable trade dispute which occurred at the beginning of this century between China and Japan resulted from this reason. The following table shows the different criteria of pesticide residues between China and the developed countries.

Table 3 Comparison of pesticide residues between China and some developed countries

\begin{tabular}{|l|l|l|l|l|}
\hline category & $\begin{array}{l}\text { National } \\
\text { Standards for } \\
\text { Pesticide } \\
\text { Residues in } \\
\text { Vegetables } \\
\text { (Items) }\end{array}$ & $\begin{array}{l}\text { pesticide } \\
\text { species }\end{array}$ & $\begin{array}{l}\text { Percentage of } \\
\text { Standard } \\
\text { Indicators for } \\
\begin{array}{l}\text { Pesticides } \\
\text { species (based } \\
\text { on CAC) }\end{array}\end{array}$ & $\begin{array}{l}\text { Percentage of } \\
\text { pesticide } \\
\text { species (based } \\
\text { on CAC) }\end{array}$ \\
\hline $\begin{array}{l}\text { Codex Alimentarius } \\
\text { Commission(CAC) }\end{array}$ & 827 & 146 & $100 \%$ & $100 \%$ \\
\hline Euro & 583 & 76 & $70.5 \%$ & $50.1 \%$ \\
\hline China & 58 & 52 & $7.0 \%$ & $35.6 \%$ \\
\hline Japan & Covers all & Covers all & & \\
\hline
\end{tabular}

\section{Source: Baidu Encyclopedia}

It can be seen from the table that developed countries, including Japan, which is the biggest target market for Yunnan vegetables, have a much stricter standard in terms of pesticide. The test items are ten times more than that of China. If China's vegetables want to enter into international markets, they have to meet at least such standards or even higher. Vegetable enterprises should know about relevant quality inspection system based on the international standards.

\section{CONCLUSION}

BRI and the establishment of China (Yunnan) Pilot Free Trade Zone in 2019 provides Yunnan Vegetable enterprises with great opportunities. Yunnan Vegetable enterprises should fully take the advantages of being the front line of opening up to promote vegetables production and management to a higher level so that more brands of vegetables can be recognized and enjoyed by people of the world.

\section{ACKNOWLEDGMENT}

Note: Funding for this research was provided by Philosophy and Social Sciences Foundation of Yunnan Province of China under grant YB2019039.

\section{REFERENCES}

[1] Zhai Fan, China's belt and road initiative: A preliminary quantitative assessment, Journal of Asian Economics Volume 55, April 2018, pp 8492

[2] Liqin Zhang, Li Zhong, Fawan Liu, Rong Qin and Weifen Li.The Status Quo of Yunnan Vegetables Exporting and Development Strategies, China Vegetables, 2012 (7): p10-12

[3] Ronghua Long , Liyun Pan, Enda Pu , Guansuo Liu , Pinglan Zhou, Problems and Consideration on Development of Vegetable Industry in Yunnan, Chinese Agricultural Science Bulletin 2013,29(20), p101-104

[4] Yingchun Zhou, Tailing Jiang, Xiankun Xiong, Dingliang Wen, Fenggui Ji , Guanghua Liu. Production Status and Prospect of Vegetable Processing Industry in Yunnan Province, Farm Products Processing, 2018(03), p66-69

[5] Jun Zhao, Jinrong Dao, Xiaolin Cai, Yueming Liu , Yongping Li, Zhenlin Zhang. Situation Introduction and Analysis on Yunnan Vegetables Exported to Singapore, Journal of Changjiang Vegetables, 2017(08), p77-80

[6] Chaojiong $\mathrm{Xu}$ and Ye Hongxia. The Advantages, Status Quo and Sustainable Strategies of Developing pollution-free Vegetable Industry in Yunnan, Journal of Zhejiang Agriculture Science,2017, 58 (12): 22522255, 2258.

[7] Ruiling Yuan,Research on China-Myanmar Agricultural Investment Cooperation under the background of Belt and Road Initiative,Journal of International Economic Cooperation, No. 7, 2017, p82-86

[8] Report on the Development of Vegetable Industry in Yunnan Province, Journal of Yunnan Agriculture 2018(7) :p25-28

[9] http://data.stats.gov.cn/easyquery.htm?cn=E010

[10] Liqin Zhang, The Statuss Quo and Development Strategies of Vegetable Export in Yunnan Province, Journal of Chinese vegetables, 2012, p11

[11] Min Hu, On the Opportunities and Challenge of Yunnan Vegetable Cold Chain Logistics Development, China observation, 2013, P22

[12] Xiaoyan Zhang, Yaqin Ye. Yunnan enhances the international competitiveness of export vegetables [N].China Food Safety News, 2013-8-3 (B01)

[13] Yingchun Zhou, Tailing Jiang, Xiankun Xiong, Dingliang Wen, Fenggui Ji, Guanghua Liu. Production Status and Prospect of Vegetable Processing Industry in Yunnan Province, Farm Products Processing, 2018(03), p66-69

[14] http//www.sohu.com/a/307200341 381560

[15] Xiaoling Yang. Impact of ASEAN Free Trade Area on Yunnan Vegetables and Brand Marketing, China Business \& Trade, 2010(07):p173-174

[16] Thomas J, Sargen. Green Barriers Trade and its Influences on China's Foreign Trade,Journal of Economic Surveys, 2006(11): 24-25.

[17]http://www.chinadaily.com.cn/china/2016twosession/201603/14/content_23850153.htm 